\title{
Pandemia y democracia, escenarios y consecuencias políticas
}

Juan Russo ${ }^{1}$

\section{a. Incertidumbres}

Un propósito constante de los actores políticos ha consistido en reducir la incertidumbre que nos ofrece el mundo. Según el teórico del poder, Mario Stoppino (2001), el fin de la política consiste en la «búsqueda de la conformidad garantizada», es decir en reducir la incertidumbre en las relaciones de poder entre los actores relevantes. La actual pandemia nos ha puesto en una situación de incertidumbre simultánea en ámbitos que atañen directamente a nuestra subsistencia: la salud y la economía, analizaremos en lo que sigue sus consecuencias políticas.

Por supuesto, la primera clase de incertidumbre radica en el propio campo de la epidemiología, donde las marchas y contra marchas de los expertos han sido frecuentes, y muchos surgidos en la propia OMS; sobre el uso general o no de barbijos, la utilidad de la estrategia del aislamiento generalizado o segmentado en casa (el dilema inglés de «estar en casa o estar alertas?», la utilidad de los test rápidos, el tipo de medicamentos a usar (ibuprofeno o paracetamol?), para no hablar de las discutibles mediciones en cada país sobre la cantidad de (y sus porcentajes) de contagiados, de muertos (medidos a veces como muertes «con»y otras «por» Corona virus) o peor aún de los recuperados; teniendo en cuenta la imponderable cantidad de asintomáticos, y de inmensas mayorias de habitantes sin haber sido testeadas, y los debates sobre pronósticos que calculan en un dos al cinco por ciento los porcenajes mayores de contagiados graves). Las afirmaciones en un sentido, y en su contrario al dia siguiente, no deben sorprender, ni desacredita a la medicina ni a los médicos; simplemente muestra que la ciencia avanza con hipótesis, $\mathrm{y}$ que ese método es insoslayable, aún en situaciones de emergencia. Mas

${ }^{1}$ Universidad de Guanajuato. Consejo Nacional de Ciencia y Tecnología (México). Contacto: esteban.tc@gmail.com 
bien, el inesperado rol de comunicadores sociales que han asumido los epidemiólogos en muchos países, frecuentemente sin contar con experiencia previa de exposición a los medios, se une a un estilo profesional de seguridad y lleva a que los expertos afirmen con autoridad médica, inferencias con bases en datos provisorios y por ende insuficientes, es decir, conjeturas que seguramente se modificarán al día siguiente.

La pandemia es para los expertos de distintos campos, y también para los ciudadanos, una ecuación con varias clases de incógnitas. La religión y la ciencia son dos formas de avanzar en la consecución de resolverlas, con procedimientos (y resultados) diferentes. Mientras la primera ofrece certezas, la segunda se aboca a(lo que Karl Popper llama) «una busqueda interminable».

\section{b. Decisiones y amenazas}

La pandemia implica el desafío de decidir de modo acertado en una situacion apremiante, tanto por la velocidad del contagio, como por las inminentes consecuencias sociales y económicas. El tiempo corto que impone la crisis para resolver, implica concentración decisional y erosiona aspectos procedimentales de las democracias vinculados a la deliberación y al control. El tiempo corto es también enemigo de un buen balance y de la buena democracia. Un balance razonable requiere distancia con los hechos, investigación, debates, comparaciones, evaluación y análisis de nuevas pruebas. En la actual emergencia, los actores evaluan y deciden simultáneamente con la ocurrencia y evolución del hecho. No es el método de la ciencia, es más bien el ejercicio (en verdad bastante frecuente, aunque negado) de la decisión política, el llamado método de «Muddling Through»(salir del paso), que resulta de la combinación de escasa información, incertidumbre y necesidad de tomar decisiones de forma inminente; el mecanismo de la política puesto al desnudo por la actual pandemia. Este proceder, en situaciones normales, se lleva a cabo entre grupos y pueden seguir cauces institucionales como los Congresos o comisiones. Por el contrario, cuando hay emergencia, las decisiones se concentran en el ejecutivo. Para los gobiernos es un riesgo y también una oportunidad. La analogía con una guerra que planteó el presidente Emmanuel Macrón, o la enorme magnitud del mayor desafío desde la segunda guerra mundial, puede ser una oportunidad como lo planteó la Canciller Angela Merkel. 
La hipótesis que aquí se sostiene es que la pandemia y la crisis económica que la acompaña, implicarán una estabilización y un reforzamiento de las tendencias políticas presentes. Esta situación ocurre en un contexto de crecimiento global de los regímenes autoritarios, como lo muestra el informe 2020 de V-Dem. Y es de esperar que aquellos países con tendencias de regresión autoritaria, se orienten hacia el establecimiento de regímenes autoritarios, como lo muestra Hungría, que atribuyó poderes especiales por tiempo indeterminado a Viktor Orban, y que implica prácticamente la suspención del Parlamento, o Polonia, que plantea llevar a cabo elecciones presidenciales virtuales, con enormes desventajas para la competencia política de la oposición. También en la Turquía de Erdogán, la pandemia ha dado lugar a deportaciones y encarcelamientos de periodistas, acusándolos de desinformar y por ende atentar contra «la salud de la población». En el mismo sentido, en el Salvador, el gobierno de Nayib Bukele, con la excusa de transgresiones a la emergencia sanitaria, ha llevado a cabo detenciones arbitrarias de opositores políticos. Como ha manifestado Kenneth Roth, director ejecutivo de Human Rights Watch: «el coronavirus es el nuevo terrorismo, es la excusa para los regímenes no democráticos o poco democráticos». En particular, es una oportunidad peligrosa para aquellos países que atraviesan por procesos de deterioro democrático, como lo muestran los casos mencionados. Nótese que en todos los casos, se trata de gobiernos con base en partidos anti establishment. Pero también es claro que la democracia muestra cierta vitalidad, y los mass media y las oposiciones ponen en muchos países de la región, límites a excesos decisionistas de los gobiernos.

La actual crisis sanitaria, no obstante el rol central de los epidemiólogos en las decisiones de los gobiernos, no ha suspendido la política en el imperio del saber técnico. La política sigue su curso en el nuevo contexto, del mismo modo que continúa en una guerra o en la lucha contra el terrorismo. Lo que cambia, es el peso del riesgo, el valor de cada decisión. Basta ver la alta capitalización política de Angela Merkel, así como el abrupto desgaste de Donald Trump. «Ganar la guerra» implica quedar en la historia de los héroes, pero no necesariamente implicará ser votado en la siguiente elección, como lo muestra el famoso caso de Winston Churchill.

En este trabajo me interesa aproximarme a las incógnitas políticas que giran en torno a las consecuencias de la pandemia sobre nuestras democracias en la región, en particular prestaré atención al caso de México. 
Para ello consideraré a)el punto cero, esto es, la situación existente al momento de producirse la pandemia, que incluye los aspectos heredados en el corto plazo, así como los vinculados con la tradición y con inercias políticas del país; b) los recursos y capacidades para afrontar la crisis, y c) la gestión de la crisis. Por último, d) se analizarán algunas consecuencias políticas generales para las democracias y en particular para el caso de México.

\section{c. El punto cero}

Al momento de llegar la pandemia, México afrontaba una combinación de situaciones difíciles. En primer lugar, el mantenimiento de altas tasas de violencia. Las cifras del 2019 calificaron al año como el más violento desde el 2006 (año de inicio de la «guerra con el narcotráfico»). Respecto al año anterior implicaron un incremento del $2,5 \%$ en la cantidad de delitos. Las tasas de asesinatos alcanzaron a 9por cada 100 mil habitantes en el Estado de Colima, y en Baja California y Guanajuato, llegaron a 5,5 y 5,3 respectivamente. En feminicidios el incremento fue aun mayor $(10,3 \%)$, los secuestros crecieron en un $3,5 \%$ y la trata de personas se incrementó en un 12,6\%. En términos de delitos en general, las extorsiones se mantuvieron en la punta de las cifras, aumentando en casi un 30\% respecto de 2018 .

En segundo lugar, una situación económica difícil, con tendencia a la recesión, como lo muestra el crecimiento cero entre 2018 y 2019, y una caída al $0.4 \%$ en el último trimestre del último año. Por otra parte, la deuda externa durante la última decada creció un $85 \%$, y abarcó en el primer trimestre de 2019 , el 36,5\% del tamaño total de la economía.

En tercer lugar, el crecimiento de la bipolarización política, derivada por una parte, de tensiones generadas en un cambio de agenda del nuevo gobierno hacia políticas de mayor integración de los sectores (socioeconómicos y étnicos) de mayor vulnerabilidad, así como al planteamiento de lograr una administración centrada en la honestidad y transparencia en la administración de los recursos ha implicado conflictos con sectores económicos de gran poder. El estilo adversarial del presidente Lopez Obrador, quien a diario expresa su repudio a la corrupción de los gobiernos anteriores, refuerza la competencia política y los conflictos.

En cuarto lugar, la situación de creciente polarización en México, tiene su contraparte en los ciudadanos, con la profundización de altas 
tasas de desconfianza hacia las instituciones públicas y estatales, en particular hacia las estructuras de representación partidarias y a las vinculadas con las instituciones de seguridad y justicia. Baste como indicador mencionar que la cifra negra del delito en México, es decir de delitos no denunciados, alcanzan al 93,5 por ciento. Es decir, el mexicano medio decide no acceder a la justicia: de cien delitos cometidos, se denuncian entre seis y siete (INEGI).

A lo anterior, agréguense factores socioeconómicos e internacionales. Alrededor del $50 \%$ de la población mexicana vive en la pobreza, y la tasa de economía informal es de más del $56 \%$. En términos internacionales, la política del presidente Trump, acentuó tendencias precedentes, con políticas anti-inmigratorias que ha significado una disminución del $2 \%$ de emigrantes mexicanos y fuertes presiones sobre México para convertirlo en «tercer país seguro» respecto de los migrantes centroamericanos, según la Convención de Ginebra sobre refugiados.

\section{d. Recursos y capacidades}

En términos de recursos políticos vinculados con el potencial decisional del presidente Andrés Manuel López Obrador (AMLO), deben mencionarse un fuerte capital político inicial, a partir de una clara victoria electoral con el $53 \%$ de los votos (el mayor apoyo electoral obtenido desde la creación del Instituto Federal Electoral en 1990), ${ }^{2}$ con una diferencia de mas de treinta puntos sobre el segundo candidato; altos niveles de aprobación en las encuestas (Mitofsky 2020) que, aunque con descensos, rondan el 50\%; mayorías legislativas en el Senado y en Diputados, y el control del gobierno de la Ciudad de México. En términos de capacidades, AMLO, es un político con experiencia de gestión, que gobernó con amplio apoyo la ciudad de México. Su experiencia previa implica que cuenta con un capital de círculos de confianza, con eficacia y que forman parte de su gabinete de decisiones. En términos de políticas públicas, su propuesta puede resumirse en el impulso a medidas de desarrollo económico, reforzamiento del rol del Estado, combate a la corrupción y apoyo a sectores vulnerables. Sus vínculos con sectores del empresariado han sido los de un gobierno moderado, que prometió no aumentar impuestos, pero su política anti evasión de impuestos le ha significado

\footnotetext{
${ }^{2}$ Se menciona esta fecha, por la incerteza jurídica de las elecciones en periodos anteriores.
} 
conflictos con grandes empresas nacionales e internacionales. El gobierno de AMLO inició el sexenio con una agenda muy precisa, que encuentra dificultades para mantenerse, y que se agravan a la luz de la imprevista emergencia sanitaria.

En términos económicos, los vinculos de actividad económica de México con Estados Unidos han crecido convirtiendose en el principal socio comercial del pais del norte, quedando en segundo y tercer lugar China y Canadá. Piénsese que sólo el intercambio económico en la frontera norte de México con Texas y California, es mayor al de Japón con Estados Unidos. El nuevo Tratado (T-MEC) implica la posibilidad de mayores inversiones en el pais con nuevas regulaciones laborales y ambientales.

En términos sociales, la experiencia de la población en la gripe A(HINl), la llamada gripe porcina, con epicentro en México en el 2009, ${ }^{3}$ implicó una experiencia colectiva de confinamiento. Por otra parte, la capacidad organizativa de las comunidades indígenas esparcidas en todo el territorio, en particular en el sur, constituyen mecanismos tradicionales de autogestión es un compensador de la pobreza y marginación que sufren, para la autoregulación colectiva en épocas de pandemia.

\section{e. La gestión de la emergencia}

En México, el presidente ha asumido una escasa centralidad respecto de la pandemia. A diferencia de políticos que vieron en la emergencia la posibiidad de un cambio de agenda, y una forma de salir del de un callejón sin salida, para AMLO, la incorporación del Covid-19 en la agenda es un obstáculo a su plan trazado, y día a día intenta mostrar que su política no cambiará demasiado. El tratamiento de la emergencia sanitaria tiene como protagonista a la Secretaría de Salud, y el Subecretario López-Gatell Ramírez rinde diariamente un informe vespertino ante la prensa.

El 11 de marzo la OMS declaró a la emergencia sanitaria del coronavirus como una pandemia, y al día siguiente AMLO informó que implementaría medidas para proteger a los sectores vulnerables acatando

\footnotetext{
${ }^{3} \mathrm{Si}$ bien fue una pandemia comparativamente menor a la actual, pues implicó alrededor de 18 mil decesos en un año y medio (OMS) mientras que a mediados del 2012 un total estimado en el mundo 150 a 575 mil fallecimientos .
} 
lo que indiquen los especialistas en salud. ${ }^{4}$ Del mismo modo no fue central su rol cuando se declaró la emergencia nacional el 30 de marzo. En el anuncio participaron la Secretaria de Gobernación Olga Sánchez Cordero (autoridad numero 2 del país) el canciller Ebrard (políticamente, el número 2 del gabinete), miembros de la Secretaría de Salud y de la Secretaría de la Defensa Nacional (SEDENA). ${ }^{5}$ Lopez Obrador, en sus mañaneras, ha instado a los empresarios a colaborar, logrando acuerdos para prórrogas en los cumplimientos de los privados, así como en políticas de no despido laboral.

La política no ha cesado pero se ha concentrado en los ejecutivos (federal y estatales), mientras que los legislativos han quedado en suspenso. El Senado dejó de sesionar el 24 de marzo y la Cámara de Diputados el 19 de marzo. Desde esas fechas los legisladores federales no han definido cómo funcionarán si continúa la emergencia. Sólocuatro congresos locales (Colima, San Luis Potosí, Baja California y Chiapas) reformaron las leyes orgánicas y reglamento internos para sesionar en forma remota; y solamente Chiapas sesionó según esas modificaciones. Otros congresos (Coahuila y Tlaxcala) han tenido sin modificar reglamentos, actividades plenarias. Algunas legislaturas han mantenido reuniones de comisiones vía remota (Ciudad de México, Guanajuato, Oaxaca, Puebla y Zacatecas). Mientras que veintiún congresos locales no han tenido actividad virtual ni han llevado a cabo reformas. ${ }^{6}$

No puede decirse que AMLO haya ganado mayor poder con la pandemia, ni que piense en capitalizar la emergencia disminuyendo los contrapesos institucionales. Más bien, su política ha estado centrada en equilibrar la necesidad de distanciamiento interpersonal por razones de salud, con los problemas que el distanciamiento plantea para el funcio-

\footnotetext{
${ }^{4}$ El presidente AMLO declaró: «Todas las decisiones que tomemos van a tener como referencia las indicaciones de los técnicos, de los científicos y de los médicos, aquí nada de política, es lo que los señores nos indiquen, porque luego por cuestiones políticas o se minimiza o se exagera, entonces vamos a hacer lo que nos recomienden los especialistas» (https://www.milenio.com/politica/Amlo-temas-conferencia-mananera-12-marzo)

${ }^{5}$ Sólo ha asumido protagonismo a nivel internacional como Jefe de Estado, con lineas políticas congruentes a la de su política interna. Así, en la reunión del G20 del 26 de marzo de 2020, propuso: que la 1. La ONU regule la distribución de medicamentos, no los grupos económicos, y pidió a los paises mas poderosos no establecer barreras arancelarias para los medicamentos, es decir, no lucar con la pandemia, 2. Apuntar a estabilizar los mercados financieros y el precio del petroleo; 3 . Rechazar toda forma de racismo y discriminación.

${ }^{6}$ http://visionlegislativa.com/congresos-virtuales-y-legalidad-en-pandemia-de-covid-19/)
} 
namiento de la economía. ${ }^{7}$ Mantener la agenda planteada al inicio choca con una brusca caída de los ingresos, como la actual, agravada por la caida estrepitosa de los precios del petróleo.

El gobierno ha asumido un rol asistencial relacionado con los efectos inmediatos sobre la salud y la actividad económica, sobre todo informal; y al mismo tiempo ha adoptado medidas para encauzar la crisis económica, y disminuir los costos políticos que puede implicar esta crisis. AMLO ha dividido claramente sus energías en tres ejes.

El primer eje es mantener su posición parte aguas «entre una clase política corrupta y una gestión de honestidad». «Las mañaneras» de cada día, en la que participa el presidente y su gabinete, pretenden ser una rendición de cuentas cotidiana ante la prensa, rompiendo con la tradición priista de distancia y opacidad en la gestión pública, aunque al mismo tiempo conservando la tradición priista de mostrar que la gobernabilidad (sólo el gobernante manda) es el primer deber de un presidente, aunque vaya en desmedro de la respondencia de actores politicamente relevantes. La posición mayoritaria en el Congreso desincentiva la idea de grandes coaliciones, pero es fundamentalmente la idea de Amlo de una gran separación ideológica y cultural con los dos principales partidos (PRI, PAN) que han gobernado México en los últimos veinte años, si se cuenta desde la alternancia, la base real de los escasos acuerdos. Las mañaneras, son políticamente la gran fábrica de la bipolarización mexicana, que se expresará en las urnas en las próximas legislativas.

El segundo eje de la gestión Amlo, está dado por la resistencia, desde un comienzo a modificar su agenda socio económica. Desde el inicio de la epidemia, Amlo intentó ganar tiempo, acelerando el T-MEC (Tratado comercial entre México, Estados Unidos y Canadá, modificando el anterior acuerdo de libre comercio NAFTA), para mantener la

\footnotetext{
${ }^{7}$ El 22 de abril Amlo anunció 11 medidas para enfrentar la crisis, entre las que se cuentan medidas de austeridad para los altos funcionarios públicos (desde subsecretarios federales hacia arriba en el escalafón), reducción del 25\% del salario, cancelación de diez subsecretarías. En lo económico, la creación de 2 millones de empleos, 3 millones de créditos a sectores de escasos recursos y clase media, la rehabilitación de las seis refinerías existentes y la construcción de la refinería de Dos Bocas, una política agresiva en la construcción de carreteras en Caminos rurales, Sistemas aeroportuarios de la Ciudad de México, Tren Maya, Tren de Guadalajara, Internet para todos, Desarrollo del istmo de Tehuantepec, entre otros, y este ambiciosos plan de obierno original, «sin aumentar el precio de los combustibles, sin aumentar impuesto o crear nuevos y sin endeudar al país» haciendo uso de «eficiencia, honestidad, y austeridad» (https://www.milenio.com/politica/coronavirus-mexico-plan-economico-Amlo-11-puntos).
} 
actividad económica, así como impulsar los principales proyectos de su sexenio: la refinería de dos bocas en Tabasco, el tren maya que uniría los estados de Chiapas, Campeche, Tabasco, Yucatán y Quintana Roo, el aeropuerto de Santa Lucía, la ampliación del actual Aeropuerto Internacional de la ciudad de México, la creación de cien universidades en regiones pobres y apartadas, la creación de una red de acceso universal a Internet, el desarrollo del tren del Itsmo de Texcoco, además de la ampliación de la cobertura social para sectores de bajos recursos.

La coordinación del gobierno federal con los gobiernos estatales ha sido débil. Si bien los informes de Lopez-Gatell son la hoja de ruta federal para cada gobierno estatal, la estrategia de diferenciación de AMLO ha llevado a una crispación cada vez más pronunciada con los gobiernos de signo distinto, en particular con los gobiernos panistas. Esta realidad se potencia por la competencia electoral para las legislativas del año próximo. También en el último tiempo sus vínculos con la Coparmex (Confederación Patronal de la República Mexicana) se han deteriorado sensiblemente, llegando a un enfrentamiento peligroso para el propio orden institucional, a tal punto que algunos analistas han hablado de intentos por parte de grupos de la Coparmex de desestabilización del gobierno). ${ }^{8}$

Por último, en términos sociales, los pueblos indígenas desde Michoacán a Guerrero, de Chihuahua a Chiapas, han bloqueado el ingreso a sus comunidades con un estricto control de los accesos apoyados en economías de subsistencia tradicionales.

\section{f. Consecuencias}

En la pandemia, el desafío más díficil de los gobiernos radica no en la entrada en la cuarentena, que implica disminuir riesgos sanitarios y el aislamiento de los ciudadanos, sino en el desconfinaliento y en la regulación del regreso a la «nueva» normalidad. La cuestión de quiénes podrán ajustarse a nuevas pautas de cuidado, respecto de los que continuarán con las limitaciones de siempre, volverá a poner sobre la mesa, las desigualdades socioeconómicas de los ciudadanos, que impactarán directamente sobre los derechos a la salud.

\footnotetext{
${ }^{8}$ https://www.eluniversal.com.mx/opinion/lorenzo-meyer/portugal-mexico-y-180deg-dediferencia
} 
En cualquier caso, la experiencia colectiva de esta emergencia sanitaria implicará cambios experienciales dificilmente reversibles. Esta pandemia muestra que hay amenazas globales que pueden llevar a la extinción de segmentos enteros de población en un tiempo extremadamente rápido, aún en regiones de relativo desarrollo, como ocurrió en la Lombardía, en Italia, convirtiendo en impotentes a los (siempre relativamente magros) recursos sanitarios.

La situación de amenaza global ya fue experimentada al inicio del nuevo siglo, con el atentado a las torres gemelas, y vale la pena detenerse un momento. Atentados hubo muchos y graves, por ejemplo en los años 70 del siglo pasado, pero se los veía localizados en ciertos lugares. El atentado terrorista del 11 de setiembre, fue un espectáculo global, que exhibió vulnerabilidad a escala global en territorios, hasta el momento, invulnerables. El planeta entero quedó comprometido por la amenaza de violencia de atentados, difundidos como nunca antes. La prevención de esa amenaza se generalizó al planeta entero, y afectó estrategias de viaje y de las fuerzas de seguridad. La diferencia con la pandemia actual, es que en el 2001 los habitantes del planeta fuimos los espectadores globales de una tragedia, mientras que ahora somos protagonistas globales, con implicancias afectivas y existenciales de calado directo y profundo. El miedo se ha convertido en experiencia directa, y pondrá seguramente a la seguridad, en un lugar prioritario, con costos seguramente sobre dimensiones liberales de la democracia, como la privacidad.

¿Cuánto el Covid-19 afectará a las democracias? ¿Cuánto modificará la política y la democracia en México? En ciencias sociales no podemos prever el futuro, no hay método científico para ello. Sólo podemos formular hipótesis a partir de comparaciones de crisis de impacto mundial. La crisis del 30 del siglo pasado trajo aparejado el New Deal de Roosvelt, y el Estado de bienestar en Europa. También implicó un nuevo modelo económico en América Latina, el modelo de industrialización por sustitución de importaciones (modelo ISI). Al mismo tiempo, la democracia dejó de ser el eje de incorporación de las masas a la política a través de los partidos, como lo fue en 1916, y el Estado nación se convirtió en el valuarte privilegiado y eje de la cultura política. Es decir, la crisis económica trajo nuevas estrategias de desarrollo, pero también coincidió con el primer golpe de estado en Argentina, y con el reforzamiento de tendencias autoritarias y totalitarias en el mundo.

Si se compara la crisis que ya se vive, con la más reciente (y que aún muestra efectos), la del 2008, hay efectos que pueden repetirse. La 
del 2008 produjo un cocktel que empeoró las democracias: a) amplió la distancia de la población respecto de los partidos políticos e instituciones representativas. Por otra parte la percepción de los ciudadanos de que los gobiernos y clase política habían optado por salvar a los bancos antes que a la población, b) reforzó la división establishment/anti establishment y segmentos amplios de ciudadanos encontraron en las propuestas nacionalistas una forma de protección contra los impactos globales del mundo financiero internacional. Sin embargo, hay también diferencias importantes entre ambas situaciones: la crisis económica del 2008 fue una crisis financiera, con responsables identificables y producida por la voracidad de altas ganancias y por la corrupción. La crisis actual es de salud, y posee un significado muy diferente: se trata de una crisis que no tiene responsables tangibles. Una devastación económica, similar a la que puede producir una catástrofe natural, y donde se espera, por parte de los actores sociales y políticamente relevantes, decisiones acertadas para reducir al máximo los costos de salud, y sus efectos colaterales. De tal modo, que si amplias capas de la población sienten que hay respondencia del gobierno, es posible que la adversidad no implique pérdida de apoyos a los gobiernos.

Respecto de México, no hay riesgos de regresión autoritaria, aunque la emergencia ha implicado el crecimiento de la competencia política y de los conflictos entre el gobierno y algunos grupos económicos y partidos.Pero no puede descontarse el alcance de acuerdos entre los dos primeros, teniendo en cuenta que la política tradicional de AMLO ha sido moderada llegando a negociaciones con beneficios recíprocos.

En términos sociales, es posible que se refuerze el comunitarismo en los estados con mayor peso de las comunidades originarias, siguiendo una tendencia con origen en Cherán (Michoacán) hace casi una década. También es interesante ver que el crimen organizado y el volumen de violencia no ha cesado durante la pandemia. Se trata de fenómenos claramente independientes de grupos cerrados que compiten por el dominio de territorios.

Es posible que la actual crisis acentúe la tendencia de disminución de la globalización. En términos politicos, el refuerzo del nacionalismo no es buena noticia para la democracia, entre otras cosas por la impunidad que pueden tener los gobiernos. La seguridad se convierte en prioritaria, y entonces el Estado tiene argumentos, relacionados con la salud de la población, para disciplinar a los ciudadanos, como en las distopías más célebres. México tiene antecedentes importantes en el último tiem- 
po en la defensa de valores liberales. Baste como ejemplo el dictamen del 2017 de la Suprema Corte de Justicia de la Nación, que concedió el amparo a cinco personas para consumir marihuana con fines lúdicos. En un fallo histórico la Corte determinó que la libertad importaba tanto como la salud. Es un antecedente importante, porque es posible que surjan a futuro amparos para proteger libertades en desmedro de la propia seguridad. Hasta el momento, la pandemia ha implicado la pérdida de derechos civiles, y hay limitaciones a la circulación de personas, $y$ dispositivos de localización de las personas. Ahora el orden y la salud pública están asociados, y se podrá argüir que se trata no de las consecuencias de la libertad de uno respecto de uno mismo, como en el caso de los cinco litigantes, sino de las libertades de uno con respecto a los demás. Así, libertades vinculadas a la privacidad, pueden ser cercenadas si se considera que lesionan derechos de terceros por amenazas potenciales del salud pública.

En términos partidarios, es previsible que la bipolarización crecerá, en parte por la situación de emergencia, donde el debate sobre la distribución de ingresos es inevitable, y ante el issue de «cómo distribuir la crisis», parece posible que el gobierno salga fortalecido ante las opciones políticas existentes. Las elecciones del $2021^{9}$ serán la prueba de fuego para la legitimidad de AMLO, donde la evaluación ciudadana sobre la gestión política (sanitaria y económico social) de la pandemia, marcarán su futuro.

\section{Referencias bibliográficas}

Stoppino, M. (2001). Potere e teoria politica. Milán, Italia: Giuffrè.

\footnotetext{
${ }^{9}$ En total estarán en disputa alrededor de tres mil doscientos cargos de elección popular, entre diputados -tanto federales como locales-, alcaldes, regidores y síndicos municipales, y de trece gobernadores, la renovación de veintisiete legislaturas estatales, y de autoridades de ayuntamientos en veintiocho estados.
} 